\title{
Coal Rock Breaking Simulation and Cutting Performance Analysis of Disc Cutters
}

\author{
Xu ZHANG*, Juan WANG, Qingguo MENG, Maolin YU, Zhenjiang ZHANG, Zhenggang GUO
}

\begin{abstract}
The coal rock breaking ability of disc cutters directly affects the construction efficiency and safety of rescue tunnels in collapsed coal rock formations. This paper establishes the plastic constitutive relationship under the Drucker-Prager (D-P) plasticity criterion, builds up a finite-element analysis (FEA) model for the coal rock breaking with a single cutter on Abaqus FEA, and explores the influence laws of different penetrations and cutting velocities on the rock breaking performance of the cutter. The results show that: as the penetration increased from $3.0 \mathrm{~mm}$ to $7.0 \mathrm{~mm}$, the mean vertical force of the cutter grew from $16.97 \mathrm{kN}$ to $23.36 \mathrm{kN}$, and the mean rolling force rose from $1.79 \mathrm{kN}$ to $3.95 \mathrm{kN}$. The increase of the cutter's vertical force improves the cutting efficiency, but intensifies the vertical impact, which undermines construction safety. As the cutting velocity increased from $0.6 \mathrm{rad} / \mathrm{s}$ to $1.5 \mathrm{rad} / \mathrm{s}$, the mean vertical force grew from $15.64 \mathrm{kN}$ to $22.94 \mathrm{kN}$, and the mean rolling force rose from $1.46 \mathrm{kN}$ to 4.23 $\mathrm{kN}$. With the increase of cutting velocity, the cutting force grew at an increasing speed. The increase of cutting velocity can improve cutting efficiency, but an excessively fast cutting velocity will weaken the stability of the cutting operation, and add to the wear of the tool. The research method provides theoretical supports to the cutterhead design of tunnel boring machine (TBM) and tunnelling control in broken coal rock formation.
\end{abstract}

Keywords: coal rock breaking principle; cutting performance; disc cutters; tunnel boring machine (TBM)

\section{INTRODUCTION}

The underground operations in coal mines are faced with harsh conditions. It is very important to ensure the work safety, for many casualties will occur if the coal mine collapses $[1,2]$. In the event of a collapse, it is difficult to excavate a rescue tunnel, owing to the fluidity of the collapsed coal seam.

Known for fast velocity of tunneling and small disturbance to the formation, tunnel boring machine (TBM) is now a preferred choice for excavating rescue tunnels, and a hotspot in the research and development (R\&D) of relevant machines [3]. The TBM relies on a cutterhead of disc cutters to dig the tunnels. To realize fast and safe tunneling in collapsed coal seam, it is necessary to study the mechanism and features of disc cutters in coal rock breaking.

In recent years, scholars at home and abroad have explored the mechanism, test methods, and process simulation of rock breaking by pick cutters or disc cutters. Their findings provide a good reference for our study on coal rock breaking. For example, Qiao et al. [4] established a reasonable constitutive model for coal rock based on empirical formulas and previous experiments, and numerically simulated the coal rock breaking process. Cardu et al. [5] carried out experiments on intermediate linear cutting machine (ILCM), compared the Colorado School of Mines (CSM) model with Norwegian University of Science and Technology (NTNU) model, and experimentally analyzed the parameters affecting the disc cutter performance in tunneling. Gertsch et al. [6] conducted cutting tests on three types of hard rocks, and examined the influence of cutter spacing and penetration on the three-way forces and specific energy of the cutter. Chang et al. [7] optimized the cutter spacing and penetration of a 17 -inch cutter for the wire cutting of granites.

Pradeep et al. [8] performed LS-DYNA finite-element simulation of rock breaking with cutter, simulated the rock breaking processes at different cutting depths and velocities, and obtained the rock breaking laws at each cutting depth and velocity. Based on the Drucker-Prager
(D-P) plastic constitutive model and mechanical properties of rock, Li et al. [9] built up a finite-element model of rock breaking with a single cutter on Abaqus FEA, and summarized the time variation of the cutting force by analyzing the rock breaking process. Through finiteelement simulation, Zhang et al. [10] investigated the influence law of cutter spacing on the degree of fragmentation, and calculated the specific energy to optimize the cutter spacing. Xia et al. [11] simulated the rock cutting process by disc cutters on LS-DYNA, and conducted comparative experiments on a rotary cutting test bench, concluding that: penetration and cutting velocity greatly affect the cutting force; the blade width has a limited impact on the rock breaking effect of disc cutters; the cutter's wear resistance can be enhanced by properly widening the cutter tip.

Taking granite as an example, Zhou et al. [12] simulated the rock breaking process with two cutters, and analyzed the breaking effect at different cutter spacing. Firstly, the constitutive relationship of granite breaking and a finite-element model of rock breaking with two cutters were established under the theory of rock breaking with cutters. Next, the rock breaking effect was analyzed under different cutter spacing, and the specific energy was calculated, revealing the optimal cutter spacing. Finally, the optimal cutter spacing was proved effective through cutting experiments on granite and basalt. Through linear cutting tests, Gong et al. [13] created an optimization model for tunneling parameters like cutting force and specific energy, and optimized cutter spacing, penetration, and tunneling velocity.

Based on extended D-P elastoplastic constitutive model, Cheng et al. [14] simulated the dynamic rock breaking process with two cutters, and verified the simulation results through rotary rock cutting experiments. Moon et al. [15] conducted discrete element simulation of the cutting process with two cutters under the changes of multiple parameters, and optimized the spacing/penetration (S/P) ratio. Labra et al. [16] combined discrete element simulation with FEA software to explore the difference between rock breaking with pre-cutting and that without pre-cutting in pressure distribution. Guo et al. 
[17] constructed a finite-element model of coal rock breaking with two cutters, and examined how the cutter spacing affects cutting force, degree of fragmentation, and specific energy under simultaneous cutting and sequential cutting.

The above studies have modeled the mechanism of rock deformation, breaking, and separation through tests and simulations. The fruitful results lay the basis and provide the ideas for our research. However, their objects are limited to hard rocks. In fact, the breaking and flowing modes of unstable coal rock greatly impact the efficiency and safety of coal mine operations. It is necessary to deeply examine the process and features of coal rock breaking with cutters.

The above studies have modeled the mechanism of rock deformation, breaking, and separation through tests and simulations. The fruitful results lay the basis and provide the ideas for our research. However, their objects are limited to hard rocks. In fact, the breaking and flowing modes of unstable coal rock greatly impact the efficiency and safety of coal mine operations. It is necessary to deeply examine the process and features of coal rock breaking with cutters.

\section{NUMERICAL SIMULATION OF COAL ROCK BREAKING WITH DISC CUTTER \\ 2.1 Coal Rock Constitutive Model}

The load features of disc cutter are closely associated with the material model of the coal rock. The constitutive relationship of coal rock is generally nonlinear. Apart from rock type, the relationship depends on stress history, loading path, and stress level. Liu et al. [18] simulated the rock breaking with cutters effectively with extended D-P model. Hence, this paper decides to adopt the extended D$\mathrm{P}$ model to simulate the constitutive relationship of coal rock.
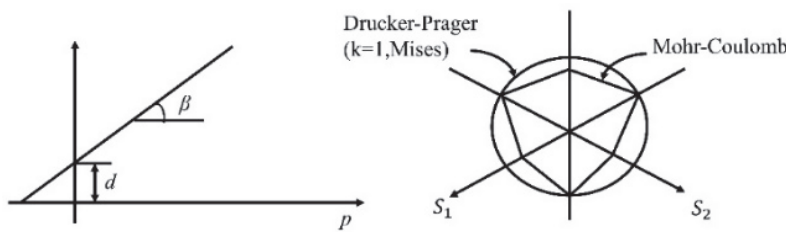

Figure 1 Extended linear D-P yield criterion in $\pi$ plane

Fig. 1 shows the yield surface of the linear D-P model. The yield function and elastic potential surface function can be respectively defined as:

$$
F=t-p \tan \beta-d=0
$$

$G=t-p \tan \varphi$

where,

$t=\frac{q}{2}\left[1+\frac{1}{k}-\left(1-\frac{1}{k}\right) \frac{r^{3}}{q}\right]$

where, $t$ is the deviatoric stress; $p$ is the equivalent compressive stress; $\beta$ is the frictional angle of the material; $d$ is the cohesive force; $\varphi$ is the dilatancy angle; $r$ is the third invariant of the deviatoric stress; $k$ is the ratio of the single-axis tensile yield stress to the single-axis compressive yield stress; $q$ is the von Mises equivalent stress.

The rock breaking with disc cutter is a typical rock failure process from deformation, damage, to bursting. This failure process was simulated by the finite-element method and unit deletion function. The rock damage model based on breaking mechanics is shown in Fig. 2, where A$\mathrm{B}$ is the material response before unit failure, $\mathrm{B}$ is the initial damage point determined by the initial damage criterion, and $\mathrm{B}-\mathrm{C}$ is the damage evolution. In the A-B segment, the material is under elastoplastic deformation. After the material stress reaches the ultimate strength, the initial damage criterion was established based on the shear failure criterion, according to the equivalent plastic strain of unit integral point:

$$
\omega_{\mathrm{s}}=\int \frac{d \bar{\varepsilon}^{p l}}{\frac{-p l}{\varepsilon_{\mathrm{s}}}\left(\theta_{\mathrm{s}}, \frac{g}{\bar{\varepsilon}}\right)}=1
$$

where, $\theta_{\mathrm{s}}=(q+K p) / \tau_{\max }$ is the shear stress rate; $\tau_{\max }$ is the maximum shear stress; $\bar{\varepsilon}^{p l}$ is the shear strain rate.

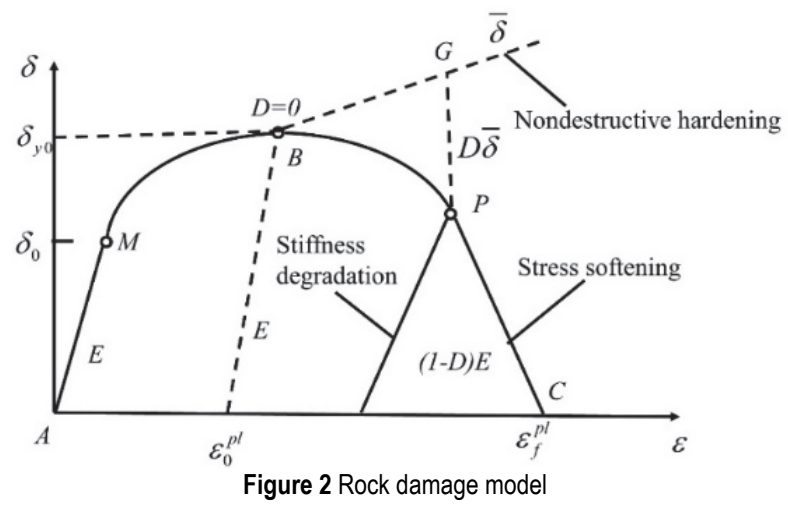

\subsection{Finite Element Modelling}

The finite-element model of the coal rock to be broken by disc cutter is illustrated in Fig. 3. The 9 inches disc cutter with structural dimensions as shown in Fig. 3a is used in this paper. The three-dimensional (3D) model of disc cutter is established in SolidWorks software, as shown in Fig. 3b. In the process of rock breaking, since the cutter ring is the only part in direct contact with the rock during the rock breaking process, components like cutter shaft and snap ring were neglected to simplify the finite-element model. In order to simulate the circumferential cutting process of coal rock middle area with the disc cutter of pipe jacking with a diameter of $1.2 \mathrm{~m}$, the coal rock structure model as shown in Fig. 3c was established in ABAQUS software. Then the model is defined as an arc structure with the inner diameter of $500 \mathrm{~mm}$, the outer diameter of $800 \mathrm{~mm}$ and the center Angle of 30 degrees to reduce the computation. Import the disc cutter model into ABAQUS, and then assemble the cutter ring and the rock according to the position relationship in the process of rock breaking, 
the three-dimensional model of rock breaking by disc cutter is shown in Fig. 3d. Considering the simulation calculation time and accuracy, the model is composed of C3D8R hexahedral elements to generate the mesh, the mesh elements were refined on the disc cutter and the coal rock area where it is rolled by disc cutter, fixed restraint is

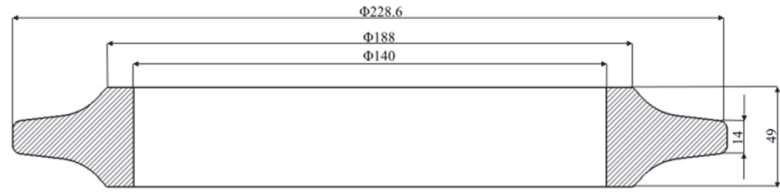

(a) Size of the 9-inch disc cutter

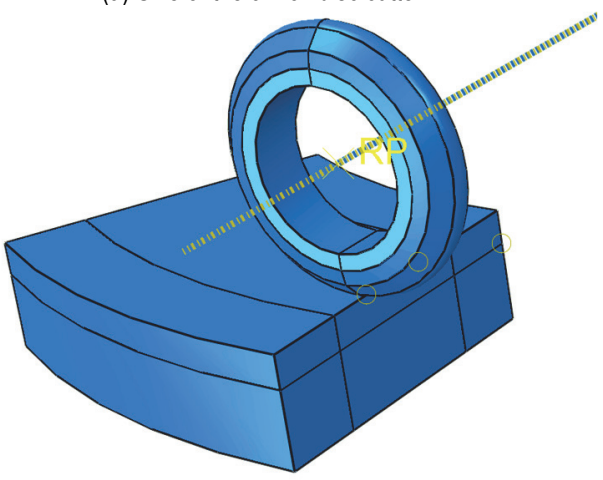

(d) Coal rock breaking model by disc cutter applied to the coal rock bottom, . The rock breaking model after meshing is shown in Fig. 3e [19].

The cutter material is set as hard alloy steel, whose density $\rho$ is $7850 \mathrm{~kg} / \mathrm{m}^{3}$, elastic modulus $E$ is $210 \mathrm{GPa}$, and Poisson's ratio $v$ is 0.3 . Material parameters of coal rock are shown in Tab. 1.

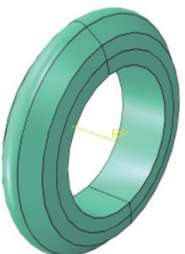

(b) Cutter mode

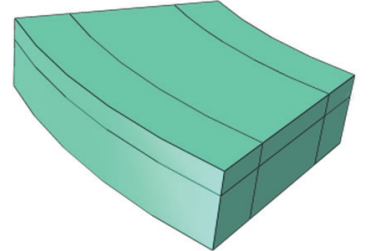

(c) Coal rock model

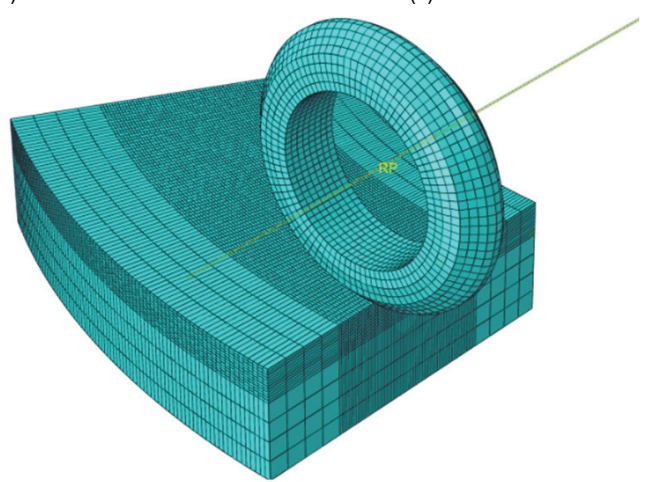

(e) Mesh model

Figure 3 The finite element model of coal rock breaking by disc cutter

Table 1 Coal rock parameters

\begin{tabular}{|c|c|c|c|c|c|}
\hline $\begin{array}{c}\text { Density } \\
\rho / \mathrm{kg} \cdot \mathrm{m}^{-3}\end{array}$ & $\begin{array}{c}\text { Elastic modulus } \\
E / \mathrm{Mpa}\end{array}$ & $\begin{array}{c}\text { Frictional angle } \\
\varphi /{ }^{\circ}\end{array}$ & Flow stress ratio & $\begin{array}{c}\text { Yield stress } \\
/ \mathrm{Mpa}\end{array}$ & $\begin{array}{c}\text { Poisson's ratio } \\
\mu\end{array}$ \\
\hline 1500 & 1400 & 30.2 & 0.778 & 20.49 & 0.3 \\
\hline
\end{tabular}

\subsection{Numerical Simulation}

The process of breaking coal rock with cutter is simulated by ABAQUS software. The cutting velocity is $1.0 \mathrm{rad} / \mathrm{s}$, the penetration is $5.0 \mathrm{~mm}$, after the simulation, the rock stress nephogram at different moments in the process of coal rock breaking is shown in Fig. 4.

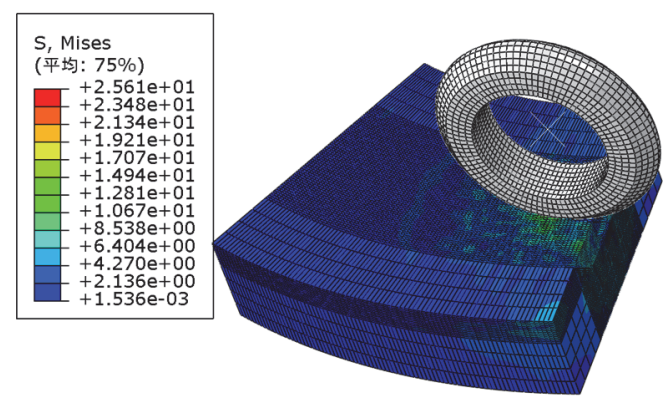

(a) $t=0.5 \mathrm{~s}$

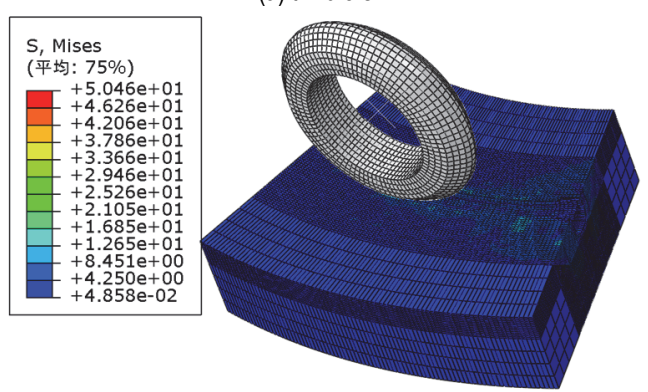

(b) $t=0.7 \mathrm{~s}$

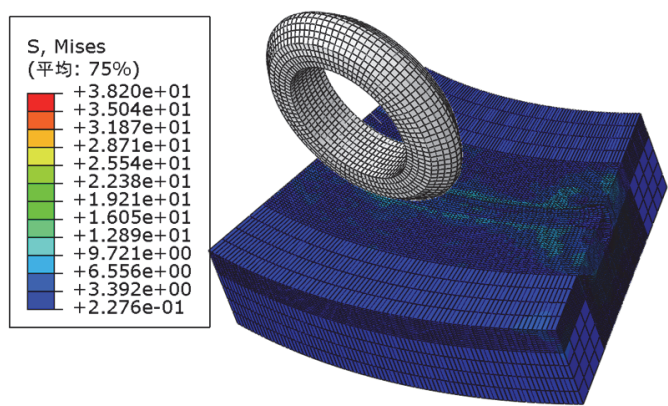

(c) $t=0.9 \mathrm{~s}$

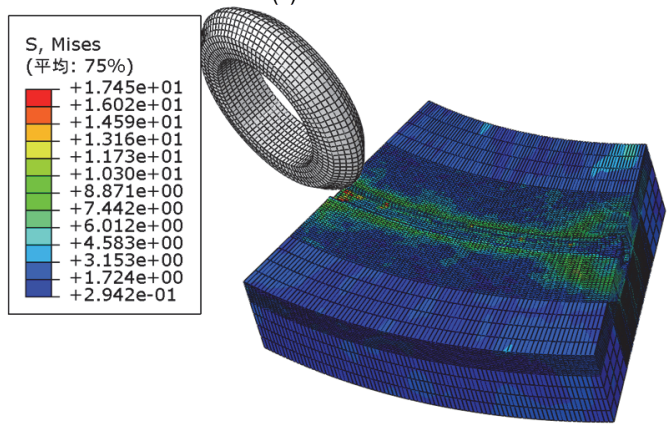

(d) $t=1.1 \mathrm{~s}$

Figure 4 Stress nephogram of rock with cutting velocity of $1.0 \mathrm{rad} / \mathrm{s}$ and penetration of $5.0 \mathrm{~mm}$

The figure shows, there is an obvious stress concentration area under the cutter, and the stress nephogram in this region is constantly changing. As the cutter continues to press, a sector stress area is formed at 
the contact area between coal rock and cutter, the area is radially distributed. The stress at the contact point between coal rock and cutter is the greatest, the further away from the contact point, the smaller the stress value, the stress distribution is approximately axisymmetric, and with the increase of cutting depth, the maximum stress also increases. After more than $1.0 \mathrm{~s}$, the stress distribution is stable, the maximum stress value is $25.61 \mathrm{MPa}$, greater than the compressive strength of coal rock, the rock surface breaks under the action of compressive stress, and constantly transferring the force to the surrounding rocks.

\subsection{Simulation Scheme}

According to the actual working conditions of TBM tunneling in coal rock stratum, the selection range of penetration is set as $3.0-7.0 \mathrm{~mm}$, and the cutting velocity is $0.6-1.5 \mathrm{rad} / \mathrm{s}$.

\begin{tabular}{|c|c|c|c|c|}
\hline Grouping & $\begin{array}{c}\text { Test } \\
\text { number }\end{array}$ & Fixed conditions & \multicolumn{2}{|c|}{ Test conditions } \\
\hline \multirow{5}{*}{ Group 1} & 1 & \multirow{5}{*}{$\begin{array}{c}\text { Cutting velocity: } 1.0 \\
\mathrm{rad} / \mathrm{s}\end{array}$} & \multirow{5}{*}{$\begin{array}{l}\text { Penetration } \\
/ \mathrm{mm}\end{array}$} & 3.0 \\
\hline & 2 & & & 4.0 \\
\hline & 3 & & & 5.0 \\
\hline & 4 & & & 6.0 \\
\hline & 5 & & & 7.0 \\
\hline \multirow{5}{*}{ Group 2} & 6 & \multirow{5}{*}{ Penetration: $4.0 \mathrm{~mm}$} & \multirow{5}{*}{$\begin{array}{c}\text { Cutting } \\
\text { velocity } / \mathrm{rad} / \mathrm{s}\end{array}$} & 0.6 \\
\hline & 7 & & & 0.8 \\
\hline & 8 & & & 1.0 \\
\hline & 9 & & & 1.2 \\
\hline & 10 & & & 1.5 \\
\hline
\end{tabular}

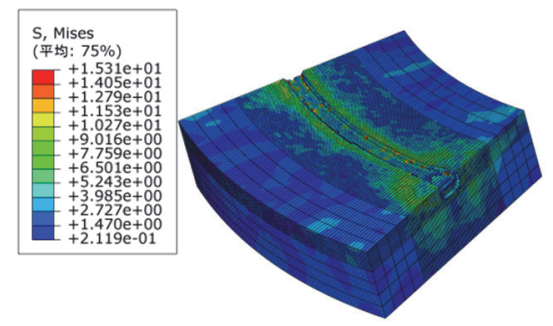

(a) $3.0 \mathrm{~mm}$

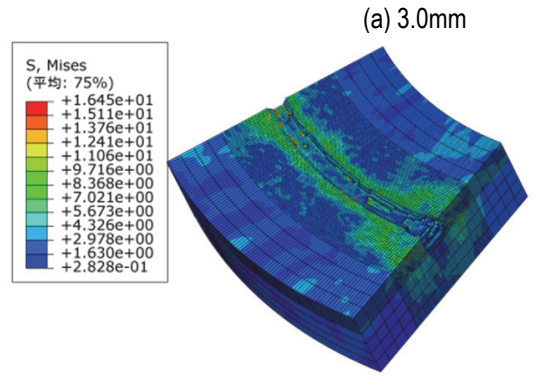

(c) $5.0 \mathrm{~mm}$

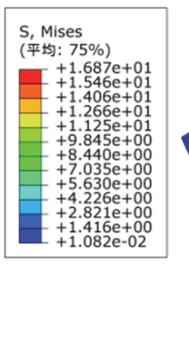

(d) $6.0 \mathrm{~mm}$

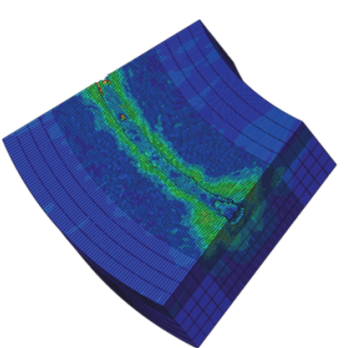

Figure 5 Broken rock surfaces under different penetrations

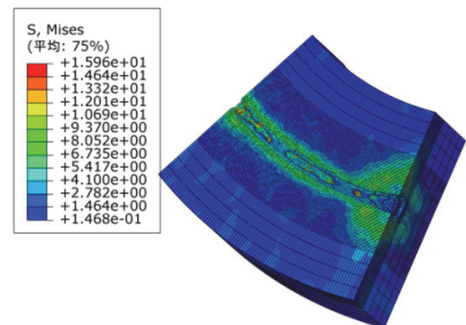

(b) $4.0 \mathrm{~mm}$ the figure that the breaking effect of cutter cutting coal rock is different under different penetration conditions. When the penetration is $3.0 \mathrm{~mm}$, as shown in Fig. $5 \mathrm{a}$, the bottom surface of the groove presents a phenomenon of lower in the middle and higher on both sides, with the increase of penetration, the height difference between the bottom surface of the groove gradually decreases. This indicates that the radial cracks and lateral cracks expand more fully, cracks are more easily connected, and coal rock is more easily broken. When the penetration increases, the more the amount of rock broken, the higher the efficiency of rock breaking.

According to the above simulation results, the data of the rolling force and vertical force changing with time under different penetrations are extracted. The average and maximum values of the mean rolling force and mean vertical force are shown in Tab. 3. The curves between the two, force and penetration, are shown in Fig. 6.

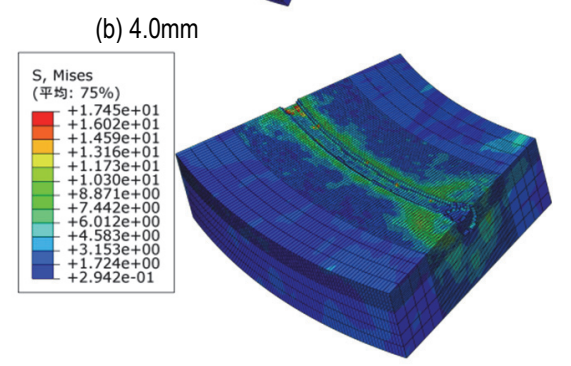

(e) $7.0 \mathrm{~mm}$

Table 3 Cutter force under different penetrations

\begin{tabular}{|c|c|c|c|c|}
\hline $\begin{array}{c}\text { Penetration } \\
/ \mathrm{mm}\end{array}$ & Mean vertical force / $\mathrm{kN}$ & Mean rolling force / $\mathrm{kN}$ & Maximum vertical force / $\mathrm{kN}$ & Maximum rolling force / $\mathrm{kN}$ \\
\hline 3.0 & 16.97 & 1.79 & 23.68 \\
\hline 4.0 & 18.31 & 2.47 & 33.02 & 12.22 \\
\hline 5.0 & 20.66 & 2.94 & 47.90 & 49.79 \\
\hline 6.0 & 22.03 & 3.46 & 20.97 & 61.15 \\
\hline 7.0 & 23.36 & 3.95 & 24.27 \\
\hline
\end{tabular}

As can be seen from Fig. 6, when penetration increases from $3.0 \mathrm{~mm}$ to $7.0 \mathrm{~mm}$, the mean vertical force on the cutter increases from $16.97 \mathrm{kN}$ to $23.36 \mathrm{kN}$, and the mean rolling force increases from $1.79 \mathrm{kN}$ to $3.95 \mathrm{kN}$. The increase of vertical and rolling forces on the cutter was accompanied with the continued increase of penetration. The vertical force increment was large at a small penetration, and small at a large penetration. On the other 
hand, with the increase of penetration, the load fluctuation caused by cutting also obviously increases, and the stability of cutter cutting decreases accordingly. When the penetration is too large, the strong impact load may cause the phenomenon of cutting edge collapse and abnormal disturbance of unstable coal stratum, which will increase the probability of tunnelling accident.

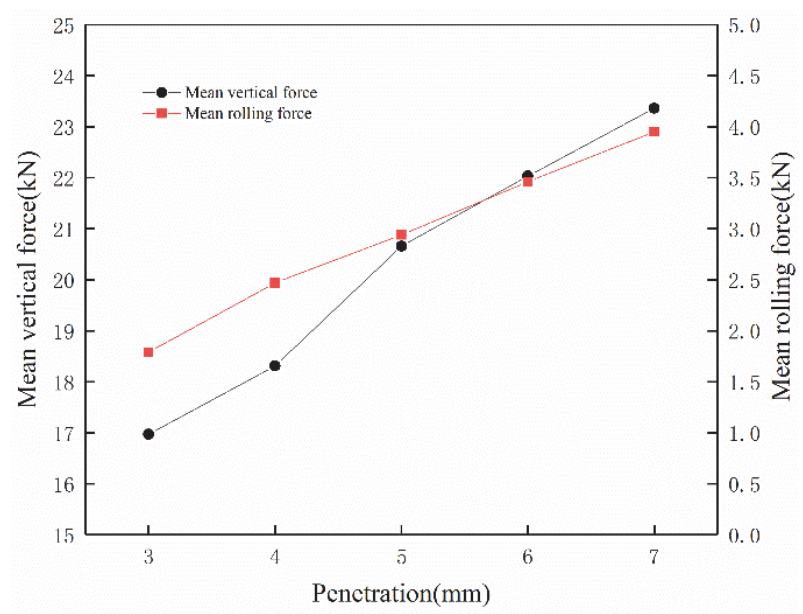

Figure 6 Cutting force-penetration curves

The mean rolling force of the cutter basically changes linearly with the penetration. As the rolling force increases, the cutter will be worn quickly, which will increase the construction cost and affect the construction efficiency. Therefore, the penetration suitable for the geological conditions of coal rock tunnelling should be considered from multiple perspectives, such as rock breaking efficiency, cutter wear and construction safety.

\subsection{Influence of Cutting Velocity on Rock Breaking Performance of Cutters}

Fig. 7 shows the broken rock surfaces' stress under different cutting velocities. As can be seen from the figure that under the different cutting velocity, the zone of the mean cutter force's action has a little change, at the same time, the maximum stress value increases with cutting velocity. It indicates, with the increase of cutting velocity, the strata disturbance e of the disc cutter on the rock surface will increase, and the intermediate and transverse cracks caused by the contact between the disc cutter and the coal rock will have the opportunity to expand greatly, forming large block of chips. Under the same penetration, the greater the cutting velocity, the greater the rock broken, and the higher breaking efficiency of coal rock will be.

Tab. 4 lists the mean rolling force and mean vertical force of the cutter at different cutting velocities. Fig. 8 presents the curves between the two forces and cutting velocity.

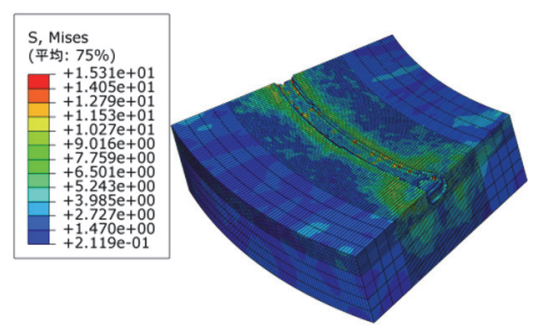

(a) $0.6 \mathrm{rad} / \mathrm{s}$

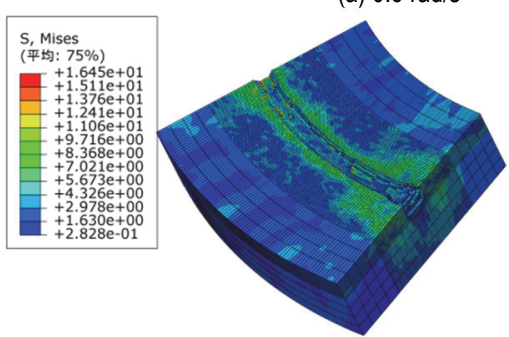

(c) $1.0 \mathrm{rad} / \mathrm{s}$

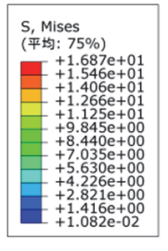

(d) $1.2 \mathrm{rad} / \mathrm{s}$

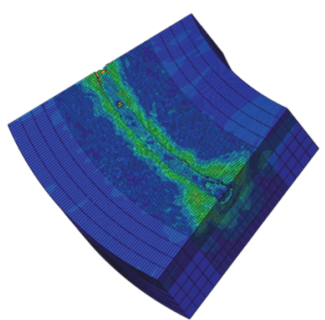

Figure 7 Broken rock surfaces under different cutting velocities

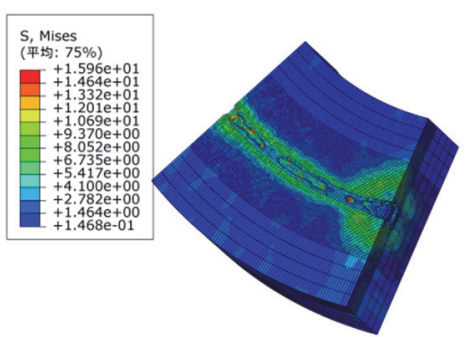

(b) $0.8 \mathrm{rad} / \mathrm{s}$

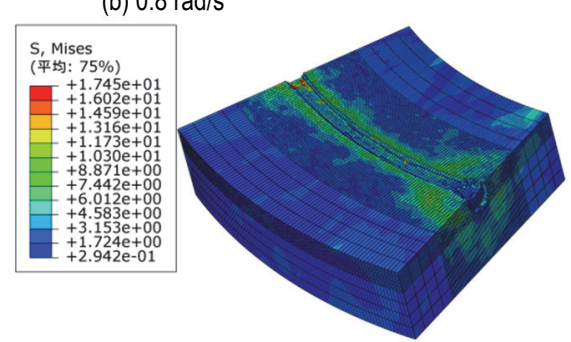

(e) $1.5 \mathrm{rad} / \mathrm{s}$

Table 4 Cutting force at different cutting velocities

\begin{tabular}{|c|c|c|c|c|}
\hline $\begin{array}{c}\text { Cutting velocities } \\
/ \mathrm{rad} / \mathrm{s}\end{array}$ & Mean vertical force $/ \mathrm{kN}$ & Mean rolling force $/ \mathrm{kN}$ & Maximum vertical force / $\mathrm{kN}$ & Maximum rolling force / $\mathrm{kN}$ \\
\hline 0.6 & 15.64 & 1.46 & 23.60 & 12.96 \\
\hline 0.8 & 16.87 & 1.92 & 29.67 & 14.65 \\
\hline 1.0 & 18.31 & 2.47 & 33.02 & 15.91 \\
\hline 1.2 & 20.58 & 3.22 & 39.11 & 18.34 \\
\hline 1.5 & 22.94 & 4.23 & 46.25 & 21.77 \\
\hline
\end{tabular}

It can be seen from Fig. 8 that when the cutting velocity increases from $0.6 \mathrm{rad} / \mathrm{s}$ to $1.0 \mathrm{rad} / \mathrm{s}$, the mean vertical force on the disc cutter increases from $15.64 \mathrm{kN}$ to $18.31 \mathrm{kN}$, and the mean rolling force increases from $1.46 \mathrm{kN}$ to $2.47 \mathrm{kN}$. When the cutting velocity increases from $1.0 \mathrm{rad} / \mathrm{s}$ to 1.5 $\mathrm{rad} / \mathrm{s}$, the mean vertical force on the disc cutter increases from $18.31 \mathrm{kN}$ to $22.94 \mathrm{kN}$, and the mean rolling force increases from $2.47 \mathrm{kN}$ to $4.23 \mathrm{kN}$. When the cutting velocity is greater than $1.0 \mathrm{rad} / \mathrm{s}$, the increase of the mean cutter force is significantly greater than that when the cutting velocity is less than $1.0 \mathrm{rad} / \mathrm{s}$. The increase of the mean cutter force accelerates with the increase of cutting velocity. 


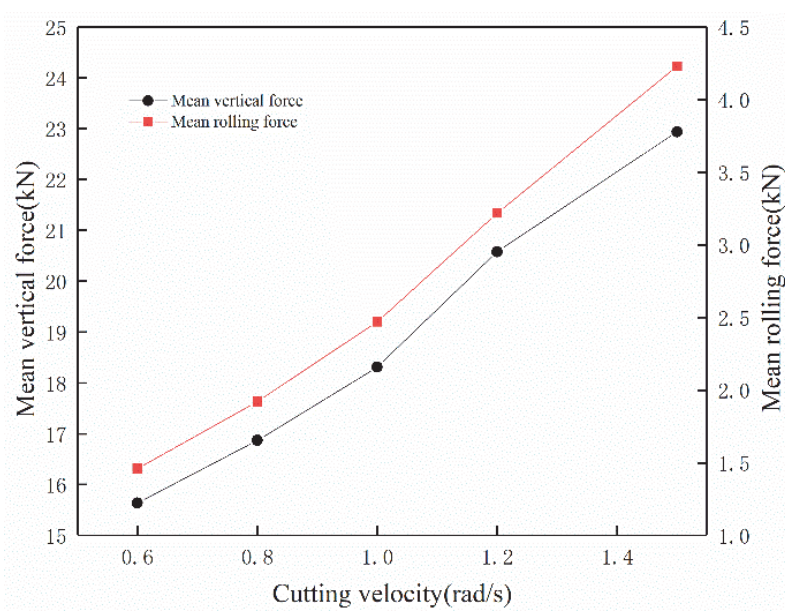

Figure 8 Cutting force-cutting velocity curves

The increase of the disc cutter's mean vertical force will lead to greater strata disturbance on coal rock, and the risk of coal rock collapse will increase. High cutting velocity even causes abnormal tool wear and failure of the disc cutter, which seriously reduces the service life of the disc cutter. Therefore, cutting velocity has an influence on coal rock breaking efficiency, tool wear and tunnelling safety.

\section{CONCLUSIONS}

This paper establishes the plastic constitutive relationship under the Drucker-Prager plasticity criterion, builds up an FEA model for the coal rock breaking with a single cutter on Abaqus FEA, and simulates the coal rock breaking process of the cutter. Then, the authors analyzed how different penetrations and cutting velocities influence the rock breaking performance of the cutter, investigated the stress cloud map, as well as the mean rolling force and mean vertical force on the cutter, and drew the influence law of penetration and cutting velocity on the cutting force for coal rock breaking with a single cutter. The main results are as follows:

(1) As the penetration increased from $3.0 \mathrm{~mm}$ to 7.0 $\mathrm{mm}$, the mean vertical force of the cutter grew from 16.97 $\mathrm{kN}$ to $23.36 \mathrm{kN}$, and the mean rolling force rose from 1.79 $\mathrm{kN}$ to $3.95 \mathrm{kN}$. The increase of the cutter's vertical force improves the cutting efficiency, but intensifies the vertical impact, which undermines construction safety.

(2) As the cutting velocity increased from $0.6 \mathrm{rad} / \mathrm{s}$ to $1.5 \mathrm{rad} / \mathrm{s}$, the mean vertical force grew from $15.64 \mathrm{kN}$ to $22.94 \mathrm{kN}$, and the mean rolling force rose from $1.46 \mathrm{kN}$ to $4.23 \mathrm{kN}$. With the increase of cutting velocity, the cutting force grew at an increasing speed. The increase of cutting velocity can improve cutting efficiency, but an excessively fast cutting velocity will weaken the stability of the cutting operation, and add to the wear of the tool.

(3) Before starting TBM operations in unstable coal rock formations, the cutting parameters should be selected reasonably in the light of the following factors: cutting efficiency, tunneling safety, and tool wear. The research method provides theoretical supports to the cutterhead design of tunnel boring machine (TBM) and tunneling control in collapsed coal mines.

\section{Acknowledgements}

This work is grateful to the financial supports from National Key R\&D Program of China (No. 2018YFC0808205).

\section{REFERENCES}

[1] Farrokh, E. (2020). A study of various models used in the estimation of advance rates for hard rock TBMs. Tunnelling and Underground Space Technology, 97, 1-14. https://doi.org/10.1016/j.tust.2019.103219

[2] Yu, Z. G., Huang, G. M., \& Zhang, C. X. (2020). Monitoring and characterization of surface deformation after the closure of coal mines based on small baseline interferometric synthetic aperture radar. Instrumentation Mesure Métrologie, 19(2), 141-150. https://doi.org/10.18280/i2m.190209

[3] He, J., Zhao, Z., Yin, Q., Luo, Y., \& Gan, X. (2020). Design and optimisation on rapid rescue well-drilling technology with large-diameter pneumatic hammers. International Journal of Mining Reclamation and Environment, 34(1), 1933. https://doi.org/10.1080/17480930.2018.1514687

[4] Qiao, S., Xia, J., Xia, Y., Liu, Z., Liu, J., \& Wang, A. (2019). Establishment of coal-rock constitutive models for numerical simulation of coal-rock cutting by conical picks. Polytechnica Civil Engineering, 63(2), 456-464. https://doi.org/10.3311/PPci.13084

[5] Cardu, M., Iabichino, G., Oreste, P., \& Rispoli, A. (2017). Experimental and analytical studies of the parameters influencing the action of TBM disc tools in tunnelling. Acta Geotechnica, 12(2), 293-304. https://doi.org/10.1007/s11440-016-0453-9

[6] Gertsch, R., Gertsch, L., \& Rostami, J. (2007). Disc cutting tests in colorado red granite: Implications for TBM performance prediction. International Journal of Rock Mechanics and Mining Sciences, 44(2), 238-246. https://doi.org/10.1016/j.jirmms.2006.07.007

[7] Chang, S., Choi, S., Bae, G., \& Jeon, S. (2006). Performance prediction of TBM disc cutting on granitic rock by the linear cutting test. Tunnelling and Underground Space Technology, 21(3-4), 271. https://doi.org/10.1016/j.tust.2005.12.131

[8] Menezes, P. L., Lovell, M. R., Avdeev, I. V., Lin, J. S., \& Higgs, C. F. (2014). Studies on the formation of discontinuous chips during rock cutting using an explicit finite element model. International Journal of Advanced Manufacturing Technology, 70(1-4), 635-648. https://doi.org/10.1007/s00170-013-5309-y

[9] Man, L. \& Li, S. (2011). Finite element numerical simulation of process of rock breaking by disc cutter. Engineering Construction, (4), 1-5. https://doi.org/10.13402/j.gcjs.2011.04.002

[10] Zhang, K., Jia, S., Sun, J., \& Zhao, H. (2019). Research on the effect of cutter spacing based on ABAQUS on rolling rock breaking efficiency. Development \& Innovation of Machinery \& Electrical Products, (3), 55-57.

[11] Xia, Y., Ouyang, T., \& Chen, L. (2012). Study on the influencing factors of the disc cutter performance. Journal of Basic Science and Engineering, 20(003), 500-507. https://doi.org/10.1007/s00170-013-5309-y

[12] Zhou, P., Guo, J., Sun, J., \& Zou, D. (2019). Theoretical research and simulation analysis on the cutter spacing of double disc cutters beaking rock. KSCE Journal of Civil Engineering, 23(7), 3218-3227. https://doi.org/10.1007/s12205-019-1777-4

[13] Gong, Q., He, G., Zhao, X., Ma, H., Li, X., Zhang, H., \& Miao, C. (2015). Influence of different cutter spacings on rock fragmentation efficiency of Beishan granite by TBM. 
Yantu Gongcheng Xuebao/Chinese Journal of Geotechnical Engineering, 37(1), 54-60. https://doi.org/10.11779/CJGE201501005

[14] Cheng, Y. (2017). Numerical simulation on optimal penetration of TBM disc cutter's rock fragmentation. Journal of Central South University (Science and Technology), 48(4), 936-943. https://doi.org/10.11817/j.issn.1672-7207.2017.04.012

[15] Moon, T. \& Oh, J. (2012). A study of optimal rock-cutting conditions for hard rock TBM using the discrete element method. Rock Mechanics and Rock Engineering, 45(5), 837 849. https://doi.org/10.1007/s00603-011-0180-3

[16] Labra, C., Rojek, J., \& Onate, E. (2017). Discrete/Finite element modelling of rock cutting with a TBM disc cutter. Rock Mechanics and Rock Engineering, 50(3), 621-638. https://doi.org/10.1007/s00603-016-1133-7

[17] Guo, Z., Wang, J., Lv S., Yu, D., \& Zhang, X. (2020). Rock breaking performance of two disc cutters of tunnel boring machine for safe tunneling in unstable coal rock stratum. International Journal of Safety and Security Engineering, 10(5), 639-646. https://doi.org/10.18280/ijsse.100508

[18] Liu, X., Xu, M., \& Qin, P. (2019). Joints and confining stress influencing on rock fragmentation with double disc cutters in the mixed ground. Tunnelling and Underground Space Technology, 83, 461-474. https://doi.org/10.1016/j.tust.2018.08.051

[19] Guo, Z., Wang, J., Lv, S., \& Zhang, X. (2020). Numerical simulation analysis of coal rock crushed by disc cutter based on ABAQUS. International Conference on Quality, Reliability, Risk, Maintenance, and Safety Engineering, Shaanxi, China, 042010. https://doi.org/10.1088/1757-899X/1043/4/042010

\section{Contact information:}

\section{Xu ZHANG}

(Corresponding author)

Institute of Mechanical Engineering and Automation,

Dalian Polytechnic University, Dalian, 116034, China

E-mail: zhangxu@dlpu.edu.cn

\section{Juan WANG}

Department of Mechanical Engineering,

Dalian University of Technology, Dalian, Liaoning, 116023, China

E-mail: 2294959766@qq.com

\section{Qingguo MENG}

Institute of Mechanical Engineering and Automation, Dalian Polytechnic University, Dalian, 116034, China E-mail: 1621385655@qq.com

\section{Maolin YU}

Institute of Mechanical Engineering and Automation, Dalian Polytechnic University, Dalian, 116034, China E-mail: buliushuchu@163.com

\section{Zhenjiang ZHANG}

Institute of Mechanical Engineering and Automation, Dalian Polytechnic University, Dalian, 116034, China E-mail:17862815661@163.com

\section{Zhenggang GUO}

Department of Mechanical Engineering,

Dalian University of Technology,

Dalian, Liaoning, 116023, China

E-mail: gzg@dlut.edu.cn 